\title{
Pathophysiology of visual disorders induced by phosphodiesterase inhibitors in the treatment of erectile dysfunction
}

This article was published in the following Dove Press journal:

Drug Design, Development and Therapy

19 October 2016

Number of times this article has been viewed

\author{
Marilita M Moschos \\ Eirini Nitoda \\ Ist Department of Ophthalmology, \\ Medical School, National \& \\ Kapodistrian University of Athens, \\ Athens, Greece
}

Aim: The aim of this review was to summarize the ocular action of the most common phosphodiesterase (PDE) inhibitors used for the treatment of erectile dysfunction and the subsequent visual disorders.

Method: This is a literature review of several important articles focusing on the pathophysiology of visual disorders induced by PDE inhibitors.

Results: PDE inhibitors have been associated with ocular side effects, including changes in color vision and light perception, blurred vision, transient alterations in electroretinogram (ERG), conjunctival hyperemia, ocular pain, and photophobia. Sildenafil and tadalafil may induce reversible increase in intraocular pressure and be involved in the development of nonarteritic ischemic optic neuropathy. Reversible idiopathic serous macular detachment, central serous chorioretinopathy, and ERG disturbances have been related to the significant impact of sildenafil and tadalafil on retinal perfusion.

Discussion: So far, PDE inhibitors do not seem to cause permanent toxic effects on chorioretinal tissue and photoreceptors. However, physicians should write down any visual symptom observed during PDE treatment and refer the patients to ophthalmologists.

Keywords: erectile dysfunction, pathophysiological mechanisms, phosphodiesterase inhibitors, PDE5, visual disorders

\section{Introduction}

\section{Phosphodiesterase inhibitors}

Phosphodiesterase type 5 (PDE5) inhibitors are considered to be the first-line therapy of erectile dysfunction. Sildenafil (Viagra ${ }^{\circledR}$; Pfizer Inc., New York, NY, USA) is a very potent inhibitor of PDE5 and of PDE6 (10-fold less potent than on PDE5), and it also suspends PDE2-4 and PDE7-11 isoenzymes. ${ }^{1,2}$ The inhibitory mechanism results in cyclic guanosine monophosphate (cGMP) elimination in cavernosal smooth muscle cells, smooth muscle relaxation, and penile erection, making the agent an effective treatment for erectile dysfunction. It is rapidly absorbed, exhibiting an oral bioavailability of $\sim 40 \%-41 \%$, and it reaches its maximal levels within $0.5-2 \mathrm{~h}$ after oral ingestion. ${ }^{1,3,4}$ The volume of distribution is $1.5 \mathrm{~L} / \mathrm{kg}$ of body weight; only $4 \%$ of its total concentration is free, and the rest is protein-bound. ${ }^{3}$ The plasma clearance of sildenafil is around $10 \mathrm{~mL} / \mathrm{min} / \mathrm{kg}$, it is predominately metabolized by liver (cytochrome P4503A4 isoenzyme), and its mean terminal half-life is 3-5 h. ${ }^{1,3}$ Drugs that are also metabolized by cytochrome P4503A4 isoenzyme, including erythromycin, ketoconazole, and cimetidine, can potentiate the effect of sildenafil. ${ }^{5}$ 
The recommended dose of sildenafil is $25-50 \mathrm{mg}$, and it can be increased to $100 \mathrm{mg}$ up to three times per week. Doses $>100 \mathrm{mg}$ elevate the frequency of adverse effects, adding no more efficacy. The sexual excitation-induced accumulation of cGMP is the precondition for the action of sildenafil, eliminating the possibilities of priapism and unwanted erections. ${ }^{5}$ The most common adverse effects of sildenafil are strongly associated with its pharmacologic nature as a PDE5 inhibitor (ie, headache, nasal congestion, flushing, and dyspepsia) and as a weak PDE6 inhibitor (ie, visual disturbances); they are dose-dependent and observed in $6 \%-18 \%$ of men taking sildenafil. ${ }^{1,5}$ The hypotensive effect of sildenafil is probably related to PDE3 inhibition. A single oral dose of $100 \mathrm{mg}$ can reduce the blood pressure by $10 \mathrm{mmHg}$, without affecting electrocardiogram. ${ }^{5}$ The simultaneous use of nitrates is obviously contraindicated. ${ }^{6}$ The high affinity of sildenafil with melanin explains its prolonged accumulation in the retina. ${ }^{3}$

The maximum concentrations of tadalafil $\left(\mathrm{Cialis}^{\circledR}\right.$; Lilly ICOS LLC, Indianapolis, IN, USA) were achieved between $30 \mathrm{~min}$ and $6 \mathrm{~h}$ and it has the longest half-life of $17.5 \mathrm{~h}$, compared to sildenafil and vardenafil (Levitra ${ }^{\circledR}$; Bayer AG, Leverkusen, Germany; and GlaxoSmithKline, Uxbridge, UK). On the other hand, the half-life of vardenafil is estimated to be $4-5 \mathrm{~h}$, and it reaches maximum plasma concentrations between $30 \mathrm{~min}$ and $2 \mathrm{~h}$. Both tadalafil and vardenafil are highly plasma protein-bound and are metabolized by P4503A4 cytochrome of the liver. The recommended starting dose for these drugs is $10 \mathrm{mg}$, increasing to a maximum dose of $20 \mathrm{mg}$ or minimum dose of $5 \mathrm{mg}$ according to their efficacy and tolerability. Tadalafil is 700fold and 9,000-fold more potent for PDE5 than for PDE6 and other PDEs, respectively, justifying the eliminated visual disturbances. Vardenafil exerts the strongest inhibition on PDE5, and it minimally affects the other PDEs. Sildenafil, tadalafil, and vardenafil act as hypotensive agents, resulting in mild decrease in systemic blood pressure. ${ }^{2}$

PDE inhibitors used in erectile dysfunction have been associated with ocular side effects, including changes in color vision and light perception, blurred vision (central haze, transitory lower vision), transient alterations in electroretinogram (ERG), conjunctival hyperemia, ocular pain, and photophobia. The color vision may be decreased, exhibiting disturbances such as colored tinges (usually blue or blue green) of objects and darker than normal colors. The bluish tinges, experienced by patients receiving sildenafil, have been related to the possible selectivity of the latter to $S$ cones. ${ }^{5}$ The alterations in light perception include raised perception of brightness and flashing lights. Raised perception of brightness and flashing lights consist of the modifications in light perception. These symptoms usually become prominent $1-2 \mathrm{~h}$ after the administration of the drugs, disappear within 3-4 h, and are dose-dependent. ${ }^{2,5}$ The prevalence of these disturbances is estimated to be $3 \%-11 \%, 50 \%$, and $100 \%$ in patients taking $25-100 \mathrm{mg}, 200 \mathrm{mg}$, and $600 \mathrm{or} 800 \mathrm{mg}$ of sildenafil, respectively. ${ }^{2}$ Questionable adverse effects involve mydriasis, retinal vascular events, and subconjunctival hemorrhage. However, PDE inhibitors do not seem to cause permanent vision damage, even in patients with preexisting vascular retinal diseases. ${ }^{5}$ The aim of this review was to present the visual disorders induced by the most common PDE5 inhibitors used for the treatment of erectile dysfunction and also to explain, in brief, the pathophysiology of such disorders.

\section{PDE family}

The contraction and relaxation of vascular smooth muscle and cardiac myocytes are regulated by the synthesis and degradation of second messengers, cyclic adenosine monophosphate or 3', $5^{\prime}$-cyclic adenosine monophosphate and cGMP. ${ }^{6,7}$ Mammalian $3^{\prime}, 5^{\prime}$-cyclic nucleotide PDEs, which are composed of 21 genes, are responsible for the degradation of cyclic nucleotides. They are classified into 11 families, based on structural similarity such as sequence homology, protein domains, and enzymatic properties, including substrate specificity, kinetic properties, and sensitivity to endogenous regulators and inhibitors. ${ }^{7}$

PDE5 is cytosolic and expressed in various tissues, including platelets and smooth and cardiac muscle; its activity is increased by protein kinase A/protein kinase $\mathrm{G}$ (PKG) phosphorylation. ${ }^{6}{ }^{6}$ PDE2, PDE5, and PDE9 isoforms are expressed in retinal pigment epithelium (RPE) cells, regulating the intracellular cGMP concentrations. The cGMP of RPE cells seems to activate the RPE pump, contributing to absorption of subretinal fluid. ${ }^{8}$ PDE5 is responsible for the modulation of atrial natriuretic peptide, kidney function, pulmonary vascular resistance, and retinal blood flow, and it is downregulated by protein phosphatase 1-mediated dephosphorylation. ${ }^{6,8,9}$ On the other hand, PKG-mediated phosphorylation, $\mathrm{Zn}^{+2}$, and allosteric cGMP binding upregulate PDE5. ${ }^{6,89}$ PDE6 is expressed in retina, where it modifies the concentrations of cGMP and visual sign transduction. The rod PDE6 holoenzyme contains one $\alpha$, one $\beta$, and two $\gamma$ subunits, and $2 \alpha$ subunits form the cone homodimer (PDE6 $\left.\alpha^{\prime}\right) .{ }^{6,7}$ Both rod and cone enzymes are found in the outer segments of photoreceptors.

The isomerization of photo pigments by the light modifies opsin, which is a membrane-bound G-proteincoupled receptor. The light-induced alterations of opsin favors the interaction of the later with an intermediate 
Guanosine-5'-triphosphate (GTP)-binding protein, called transducin (T).$^{5-7}$ Each photon absorbed by pigments activates $\sim 500$ molecules of T. ${ }^{5}$ GTP binds to T, after the dissociation of GDP, provoking the break of $\mathrm{T}$ into T $\alpha$-GTP and a T $\beta \gamma$ complex. ${ }^{6}$ Each T $\alpha-G T P$ complex stimulates many PDE6 molecules, removing the inhibitory subunit $\gamma$, which inhibits PDE6 activity in the absence of light stimulation. ${ }^{5-7}$ The active PDE6 induces the reduction of cGMP levels in photoreceptors, the closure of sodium channels in the outer segment cell membrane (of photoreceptors), the membrane hyperpolarization, and the inception of light transduction. ${ }^{5,6}$ If the time of high cGMP levels is prolonged, a possible toxicity of the photoreceptors can occur. ${ }^{5}$ Sildenafil, vardenafil, and avanafil, but not tadalafil, inhibit PDE6 with substantially lower affinities than those for PDE5A. Mutations in genes generating defective PDE6 enzymes (mainly rod PDE6 $\alpha \beta$ ) result in high level of cGMP photoreceptor cell death. ${ }^{7}$

\section{Pathophysiology and vision disorders \\ Effects on anterior chamber and intraocular pressure}

Although sildenafil citrate seems to have a hypotensive effect on systolic and diastolic blood pressure, it causes a temporary increase in intraocular pressure (IOP). Specifically, Gerometta et al noted that IOP was raised by $26 \%$ in subjects who ingested $100 \mathrm{mg}$ sildenafil citrate and returned to normal levels within $2 \mathrm{~h}$, whereas the systolic and diastolic pressures reduced by $15 \%$ and $13 \%$, respectively. ${ }^{10}$ The same group study had previously highlighted that sildenafil (in dose of 50 or $100 \mathrm{mg}$ ) induced 1.6-fold elevation of IOP in sheep within $1 \mathrm{~h}$ after ingestion, which lasted for $4 \mathrm{~h} .{ }^{11} \mathrm{On}$ the other hand, the IOP was increased by 1.9 times within $48 \mathrm{~h}$ after the consumption of $20 \mathrm{mg}$ tadalafil by the sheep, and it was restored within 4 days. ${ }^{11}$ The aqueous humor protein was also raised by $39 \%$ along with IOP elevation.

These vasodilators probably induce an increase in volume, flow, and pressure in the precapillary arterioles, augmenting the pressure difference between the ciliary body stroma and the anterior chamber and facilitating the aqueous humor inflow within the anterior chamber. ${ }^{11}$ This theory is confirmed by the observations that sildenafil restores aqueous humor refilling after anterior chamber paracentesis, resulting in IOP recovery. ${ }^{11-13}$ However, a previous study by Grunwald et al had revealed that the maximum therapeutic dose of sildenafil of $100 \mathrm{mg}$ caused no statistically significant change in IOP or systemic blood pressure in men having treated chronic open-angle glaucoma. ${ }^{14}$

\section{Nonarteritic anterior ischemic optic neuropathy}

Sildenafil consumption has been associated with anterior nonarteritic ischemic optic neuropathy (NAION). Moschos and Margetis noted the simultaneous presentation of NAION in a 55-year-old man, who had received $50 \mathrm{mg}$ of sildenafil four to five times a month, over the previous 8 months. ${ }^{15}$ The examination at presentation revealed a visual acuity of 0.7 and 0.9 in the right and left eyes, respectively, a right optic disk edema, a left crowded optic disk, and an inferior altitudinal defect in visual fields of both the eyes. Three weeks after the discontinuation of the drug, both visual acuity and optic disc features were restored, but the visual field defect of the right eye remained unchanged, lasting even 3 months later. ${ }^{15}$

Similarly, Tarantini et al diagnosed anterior NAION in a 60-year-old man with diabetes, who took one $50 \mathrm{mg}$ tablet sildenafil for 3 consecutive days, neglecting his antiglycemic medication on the third day. ${ }^{16}$ They identified low visual acuity, optic disc edema, and peripapillary nerve fiber layer hemorrhages in both eyes, along with serous macular detachment in the right eye and peripapillary cotton wool spots in the left eye. Visual field defects were also detected in both the eyes (superior altitudinal and central defects in the right eye and inferior altitudinal defect in the left eye). Two weeks after the last steroid administration, visual acuity and fundus findings were improved, but the visual field defects remained immutable. ${ }^{16}$ The combination of hyperglycemia and activated cGMP-dependent PKG, induced by the inhibition of PDE5, was associated with the enhancement of nitric oxide (NO) pathway and the upregulation of vascular endothelial growth factor gene. These changes seem to stimulate angiogenesis and vascular permeability, resulting possibly in edema, breakdown of the blood-ocular barrier, and NAION lesions. ${ }^{16}$

Felekis et al noted unilateral NAION in a 51-year-old man $12 \mathrm{~h}$ after receiving sildenafil citrate. ${ }^{17}$ His history revealed the use of sildenafil for the last 6 months at least once a week, as well as mild hypercholesterolemia. One year after receiving three steroid injections and the discontinuation of sildenafil, visual acuity was significantly improved, but the visual field tests were not. ${ }^{17}$ Episodes of transient blurring of the visual field may be the precursor for an anterior NAION event, following the ingestion of tadalafil for few times. ${ }^{18}$ In fact, one patient experienced NAION when he received his fifth dose of $20 \mathrm{mg}$ tadalafil within 1 month. ${ }^{18}$ Besides anterior NAION, the physicians and ophthalmologists should be aware of PDE5 inhibitor-induced atypical and 
posterior NAION, which can be misdiagnosed and hampers the treatment. ${ }^{19,20}$

\section{Chorioretinal alterations and toxicity}

Idiopathic serous macular detachment (SMD), being accompanied with perimacular vitelliform deposits, has been already related to sildenafil citrate use, which possibly induces idiosyncratic dilation of retinal and choroidal vessels and leads to leakage across the RPE and accumulation of subretinal fluid. ${ }^{21}$ The partial or complete resolution of SMD and vitelliform deposits after the cessation of sildenafil and the recurrence of SMD following the restart of this agent confirm the implication of the medication in SDM pathogenesis. ${ }^{21}$ Tadalafil administration was also implicated in the development of thickened and markedly hyperreflective areas in the photoreceptors' internal-outer segment interface, being accompanied with a serous retinal detachment-like appearance. ${ }^{22}$ The cessation of the drug resulted in the disappearance of these findings, as detected by spectral domain optical coherence tomography (SD-OCT). ${ }^{22}$

The detection of central serous chorioretinopathy (CSC) during sildenafil therapy should also be a reason for recommending discontinuation of the medication, taking into consideration that any recurrence is possible if the therapy resumes. ${ }^{23}$ A case of CSC, $24 \mathrm{~h}$ after the use of $>20 \mathrm{mg}$ tadalafil (daily dose, $2.5-20 \mathrm{mg}$ ), has also been reported. The discontinuation of tadalafil resulted in improvement in visual acuity and subretinal fluid. ${ }^{24}$ Acar et al also diagnosed CSC in a 47-year-old male patient, who received $20 \mathrm{mg}$ of tadalafil for erectile dysfunction three times on alternate days, despite his urologist recommending $20 \mathrm{mg}$ two times per week. However, they observed that the visual acuity and the retinal anatomy were rehabilitated 2 weeks after the discontinuation of the drug. ${ }^{25}$ The vasodilator effect of tadalafil was related to a painful red eye, subretinal and intratumoral hemorrhage, and intratumoral vascular congestion, detected in a patient with a malignant melanoma of the ciliary body and choroid, after receiving a single tadalafil tablet. ${ }^{26}$ Tadalafil may also participate in the development of concurrent central retinal artery occlusion in patients with additional risk factors, such as sickle cell disease. ${ }^{27}$

Yuan et a ${ }^{28}$ studied the mechanism of sildenafil-induced dilation of retinal vessels, and they revealed that it is dose-dependent. They observed that sildenafil activates the synthase of NO, via extracellular signal-regulated kinase signaling, resulting in NO production and guanylyl cyclase activation. The following accumulation of cGMP within vascular smooth muscles elicits the opening of the selective adenosine triphosphate-sensitive potassium channels in some types of vasculatures. This cascade is implicated in vasorelaxation, achieved through the inhibition of transmembrane influx of calcium and the membrane hyperpolarization. Moreover, they highlighted that the clinical doses of sildenafil do not cause potent vasodilation in retinal arterioles, but sildenafil seems to have a significant impact on retinal perfusion. They observed that $10 \mathrm{ng} / \mathrm{mL}$ of sildenafil is the threshold concentration for the dilation of retinal arterioles, whereas, even in the highest concentration $(1 \mu \mathrm{g} / \mathrm{mL})$, the elicited dilation reaches $30 \%$ of the maximum. ${ }^{28}$

Increase in choroidal perfusion and thickness has been recorded by enhanced depth imaging SD-OCT and sweptscan high-frequency digital ultrasound, $1-3 \mathrm{~h}$ after ingesting 50-100 mg of sildenafil. ${ }^{29,30}$ Kurtulan et a ${ }^{31}$ noted that although sildenafil increases mean cavernous artery peak systolic flow velocity and also reduces systolic and diastolic systemic arterial blood pressures, it has no effect on central retinal artery circulation, even in subjects with ocular side effects. The alterations in choroidal perfusion and the inhibition of PDE6 induced by sildenafil were associated with the ocular symptoms. ${ }^{31}$ In fact, sildenafil citrate downregulates the expression of PDE6 in a dose- and time-dependent manner. ${ }^{32}$ The absence of ERG disturbances in dogs after avanafil (Stendra $^{\mathbb{}}$; Vivus, Mountain View, CA, USA) administration, due to its high selectivity for PDE5, confirms the implication of PDE6 in ocular side effects induced by the medications (sildenafil and tadalafil) for erectile dysfunction..$^{33}$ Moreover, a single $100 \mathrm{mg}$ dose of sildenafil seems to be well tolerated even in patients with early-stage age-related macular degeneration (AMD), producing no significant visual impairment or disturbances in Amsler grid, color discrimination (D15), traffic light, Humphrey perimetry, and photostress testing. ${ }^{34}$

Luu et $\mathrm{al}^{35}$ recorded depressed but normal full-field and multifocal cone ERGs in macula and periphery after the administration of $200 \mathrm{mg}$ of sildenafil. The maximal a-wave and the cone b-wave were delayed, and the amplitude of the latter was also reduced. However, increased maximal scotopic b-wave was measured. In addition, it was noted that the $\mathrm{P}_{1}$ amplitude was decreased, and the implicit time was prolonged in multifocal ERG. Furthermore, color testing disturbances were revealed and correlated with the ocular symptoms, including changes in light sensitivity, bluetinted vision, headache, flushing, and nausea. ${ }^{35}$ Prolonged implicit times of rod (maximum response a-wave) and cone (oscillatory potentials, cone response b-wave, $30 \mathrm{~Hz}$ flicker 
and $3.3 \mathrm{~Hz}$ flicker a-wave and b-wave) ERG responses in subjects receiving a single $100 \mathrm{mg}$ dose of sildenafil were also recorded by Jägle et al. ${ }^{36}$ They detect no significant differences -either in cone contrast sensitivity -or in Rayleigh (red green) and Moreland (blue green) color matches between group receiving sildenafil and placebo group. ${ }^{24}$ However, the thresholds on the static yellow background testing transient tritanopia were lower for the sildenafil group, whereas the rod responses $1 \mathrm{~h}$ after sildenafil dose were raised. ${ }^{36}$

Similarly, two more studies supported a higher rod sensitivity (decrease in $\mathrm{K}$ ) and response to light stimuli, as recorded by ERG 1 and $2 \mathrm{~h}$ after ingesting 50 and $100 \mathrm{mg}$ of oral sildenafil, respectively. ${ }^{37,38}$ Furthermore, the daily use of sildenafil at doses 120-300 mg for 1-4 years did not reveal any toxic effect on photoreceptors of the studied patients by Zoumalan et al. ${ }^{39}$ They noted normal color vision testing and amplitudes in full-field and multifocal ERG, although cone flicker implicit times were modestly prolonged. The mild alterations in ERG seem to be restored a few hours after the administration of the drug, indicating that any possible retinal toxicity of sildenafil may be reversible in the short term. ${ }^{39,40}$ Together, Cordell et al highlighted that the daily consumption of $5 \mathrm{mg}$ of tadalafil or $50 \mathrm{mg}$ of sildenafil for 6 months was not associated with visual disturbances or retinal toxicity, as assessed by ERG, visual acuity, number of errors in color discrimination testing, automated visual field testing, and IOP. ${ }^{41}$ However, sildenafil exhibits a frequency-independent attenuation of the visual signal, interfering in the ability of PDE6 to shorten the time over which the visual system integrates signals as the light level increases. ${ }^{42}$ Stockman et al identified some losses in sensitivity of S-, M- and L-cones in two patients who received a single dose of $100 \mathrm{mg}$ of sildenafil, without supporting that the drug administration can impair common visual tasks. ${ }^{42}$

\section{Other optical disturbances}

Assessing the ocular impact of sildenafil, Dündar et $\mathrm{al}^{43}$ examined 15 patients with erectile dysfunction who received $50 \mathrm{mg}$ of sildenafil two times a week for 3 months, based on best-corrected visual acuity (BCVA), IOP, color vision, anterior segment, and fundus examination, along with blueon-yellow $(B / Y)$ and white-on-white (W/W) Humphrey perimetry and color Doppler imaging. They observed that long-term use of the drug had no effects on BCVA, IOP, color vision, or $\mathrm{B} / \mathrm{Y}$ and $\mathrm{W} / \mathrm{W}$ Humphrey perimetry, whereas no abnormalities of anterior segment and fundus were found. ${ }^{43,44}$ Furthermore, no alterations of ocular hemodynamics in ophthalmic, central retinal, and short posterior ciliary arteries were detected. ${ }^{44}$ However, the hypotensive effect of sildenafil can be responsible for the complete pupil sparing third nerve palsy in patients with preexisting microvascular disease. ${ }^{45}$ The transient hypoperfusion of the third nerve seems to be the cause for the neuro-ophthalmologic manifestations.

Besides adults' side effects, sildenafil is suspected to exacerbate retinopathy of prematurity, but it has not been associated with ocular complications observed in neonates with persistent pulmonary hypertension under sildenafil treatment. ${ }^{46}$ The ocular safety of chronic sildenafil administration in patients with pulmonary arterial hypertension was also evaluated by a double-masked, randomized, placebocontrolled, Phase III trial with open-label extension study, which was conducted by 53 institutions. Two hundred and twenty-seven adults with idiopathic or secondary pulmonary hypertension received placebo, 20, 40, or $80 \mathrm{mg}$ of oral sildenafil three times daily for 12 weeks and underwent ocular examination at 3,6, and 18 months. The sildenafil treatment was not associated either with disturbances in visual acuity, contrast sensitivity, color vision, and IOP -or with visual field defects during the study period. ${ }^{47}$

\section{Conclusion}

So far, PDE inhibitors do not seem to cause permanent toxic effects on chorioretinal tissue and photoreceptors. However, physicians should write down any visual symptom observed during PDE treatment and refer the patients to ophthalmologists. Furthermore, more studies are required to be carried out in order to confirm the transient nature of visual adverse effects.

\section{Acknowledgments}

The authors alone are responsible for the content and writing of this paper, and they have contributed significantly to this manuscript. No financial support was obtained for the present manuscript.

\section{Disclosure}

The authors report no conflicts of interest in this work.

\section{References}

1. Shindel A, Brant WO, Bochinski D, Bella AJ, Lue TF. Medical and surgical therapy of erectile dysfunction. In: De Groot LJ, Beck-Peccoz P, Chrousos G, et al, editors. Endotext [Internet]. South Dartmouth (MA): MDText.com, Inc.; 2000.

2. Goldstein I, Lue TF, Padma-Nathan H, Rosen RC, Steers WD, Wicker PA. Oral sildenafil in the treatment of erectile dysfunction. Sildenafil Study Group. N Engl J Med. 1998;338:1397-1404.

3. Omori K, Kotera J. Overview of PDE and their regulation. Circ Res. 2007; 100:309. 
4. Beavo JA. Cyclic nucleotide phosphodiesterases: functional implications of multiple isoforms. Physiol Rev. 1995;75:725-748.

5. Diederen RM, La Heij EC, Markerink-van Ittersum M, Kijlstra A, Hendrikse F, de Vente J. Selective blockade of phosphodiesterase types 2,5 and 9 results in cyclic $3^{\prime} 5^{\prime}$ guanosine monophosphate accumulation in retinal pigment epithelium cells. Br J Ophthalmol. 2007;91(3): 379-384.

6. Marmor MF, Kessler R. Sildenafil (Viagra) and ophthalmology. Surv Ophthalmol. 1999;44:153-162.

7. Lin CS, Lin G, Xin ZC, Lue TF. Expression, distribution and regulation of phosphodiesterase 5. Curr Pharm Des. 2006;12:3439.

8. Kerr NM, Danesh-Meyer HV. Phosphodiesterase inhibitors and the eye. Clin Exp Ophthalmol. 2009;37:514-523.

9. Glossmann H, Petrischor G, Bartsch G. Molecular mechanisms of the effects of sildenafil (VIAGRA). Exp Gerontol. 1999;34:305-318.

10. Gerometta R, Alvarez LJ, Candia OA. Effect of sildenafil citrate on intraocular pressure and blood pressure in human volunteers. Exp Eye Res. 2011;93(1):103-107.

11. Gerometta R, Alvarez LJ, Candia OA. Effects of sildenafil and tadalafil on intraocular pressure in sheep: implications for aqueous humor dynamics. Invest Ophthalmol Vis Sci. 2010;51(6):3139-3144.

12. Gerometta R, Alvarez LJ, Candia OA. Sildenafil accelerates anterior chamber refilling after paracentesis in sheep and rabbits. Invest Ophthalmol Vis Sci. 2012;53(2):565-573.

13. Alvarez LJ, Zamudio AC, Candia OA. Sildenafil stimulates aqueous humor turnover in rabbits. Exp Eye Res. 2013;111:67-70.

14. Grunwald JE, Jacob SS, Siu K, Piltz J, Dupont J. Acute effects of sildenafil citrate (Viagra) on intraocular pressure in open-angle glaucoma. Am J Ophthalmol. 2001;132(6):872-874.

15. Moschos MM, Margetis I. Bilateral simultaneous anterior ischemic optic neuropathy associated with sildenafil. Case Rep Ophthalmol. 2011; 2(2):262-265.

16. Tarantini A, Faraoni A, Menchini F, Lanzetta P. Bilateral simultaneous nonarteritic anterior ischemic optic neuropathy after ingestion of sildenafil for erectile dysfunction. Case Rep Med. 2012;2012: 747658.

17. Felekis T, Asproudis I, Katsanos K, Tsianos E. A case of nonarteritic anterior ischemic optic neuropathy of a male with family history of the disease after receiving sildenafil. Clin Ophthalmol. 2011;5:1443-1445.

18. Bollinger K, Lee MS. Recurrent visual field defect and ischemic optic neuropathy associated with tadalafil rechallenge. Arch Ophthalmol. 2005; 123(3):400-401.

19. Cullen JF, Chung HW. Mistaken diagnosis of optic neuritis and the possible role of phosphodiasterase-5 inhibitors (Sildenafil/Viagra). Med J Malaysia. 2010;65(4):315-316.

20. Karli SZ, Liao SD, Carey AR, Lam BL, Wester ST. Optic neuropathy associated with the use of over-the-counter sexual enhancement supplements. Clin Ophthalmol. 2014;8:2171-2175.

21. Quiram P, Dumars S, Parwar B, Sarraf D. Viagra-associated serous macular detachment. Graefes Arch Clin Exp Ophthalmol. 2005; 243(4):339-344.

22. Coscas F, Coscas G, Zucchiatti I, Bandello F, Soubrane G, Souïed E. Optical coherence tomography in tadalafil-associated retinal toxicity. Eur J Ophthalmol. 2012;22(5):853-856.

23. Fraunfelder FW, Fraunfelder FT. Central serous chorioretinopathy associated with sildenafil. Retina. 2008;28(4):606-609.

24. Gordon-Bennett P, Rimmer T. Central serous chorioretinopathy following oral tadalafil. Eye (Lond). 2012;26(1):168-169.

25. Acar U, Kucuk B, Agin A, Koc M, Sobaci G. Case report of tadalafilinduced central serous chorioretinopathy. J Clin Exp Ophthalmol. 2014;5:357.

26. Abramson DH, Rollins IS, Lin A, Odell P, Folberg R. Tadalafil-induced subretinal and choroidal hemorrhage in a patient with an unsuspected uveal (choroidal and ciliary body) melanoma. Arch Ophthalmol. 2006; 124(7):1058-1060.
27. Murthy RK, Perez L, Priluck JC, Grover S, Chalam KV. Acute, bilateral, concurrent central retinal artery occlusion in sickle cell disease after use of tadalafil (Cialis). JAMA Ophthalmol. 2013;131(11):1471-1473.

28. Yuan Z, Hein TW, Rosa RH Jr, Kuo L. Sildenafil (Viagra) evokes retinal arteriolar dilation: dual pathways via NOS activation and phosphodiesterase inhibition. Invest Ophthalmol Vis Sci. 2008;49(2):720-725.

29. Kim DY, Silverman RH, Chan RV, et al. Measurement of choroidal perfusion and thickness following systemic sildenafil (Viagra(®)). Acta Ophthalmol. 2013;91(2):183-188.

30. Vance SK, Imamura Y, Freund KB. The effects of sildenafil citrate on choroidal thickness as determined by enhanced depth imaging optical coherence tomography. Retina. 2011;31(2):332-335.

31. Kurtulan E, Gulcu A, Secil M, Celebi I, Aslan G, Esen AA. Effects of sildenafil on ocular perfusion demonstrated by color Doppler ultrasonography. IntJ Impot Res. 2004;16(3):244-248.

32. Gonzalez CM, Bervig T, Podlasek C, Huang CF, McKenna KE, McVary KT. Sildenafil causes a dose- and time-dependent downregulation of phosphodiesterase type 6 expression in the rat retina. Int J Impot Res. 1999;11(Suppl 1):S9-S14.

33. Mochida H, Yano K, Inoue H, Yee S, Noto T, Kikkawa K. Avanafil, a highly selective phosphodiesterase type 5 inhibitor for erectile dysfunction, shows good safety profiles for retinal function and hemodynamics in anesthetized dogs. J Urol. 2013;190(2):799-806.

34. Birch DG, Toler SM, Swanson WH, Fish GE, Laties AM. A double-blind placebo-controlled evaluation of the acute effects of sildenafil citrate (Viagra) on visual function in subjects with early-stage age-related macular degeneration. Am J Ophthalmol. 2002;133(5):665-672.

35. Luu JK, Chappelow AV, McCulley TJ, Marmor MF. Acute effects of sildenafil on the electroretinogram and multifocal electroretinogram. Am J Ophthalmol. 2001;132(3):388-394.

36. Jägle H, Jägle C, Sérey L, et al. Visual short-term effects of Viagra: double-blind study in healthy young subjects. Am J Ophthalmol. 2004; 137(5):842-849.

37. Balacco Gabrieli C, Regine F, Vingolo EM, Rispoli E, Isidori A. Acute electroretinographic changes during sildenafil (Viagra) treatment for erectile dysfunction. Doc Ophthalmol. 2003;107(2):111-114.

38. Gabrieli CB, Regine F, Vingolo EM, Rispoli E, Fabbri A, Isidori A. Subjective visual halos after sildenafil (Viagra) administration: electroretinographic evaluation. Ophthalmology. 2001;108(5):877-881.

39. Zoumalan CI, Zamanian RT, Doyle RL, Marmor MF. ERG evaluation of daily, high-dose sildenafil usage. Doc Ophthalmol. 2009;118(3): 225-231.

40. Kinoshita J, Iwata N, Shimoda H, Kimotsuki T, Yasuda M. Sildenafil induced reversible impairment of rod and cone phototransduction in monkeys. Invest Ophthalmol Vis Sci. 2015;56(1):664-673.

41. Cordell WH, Maturi RK, Costigan TM, et al. Retinal effects of 6 months of daily use of tadalafil or sildenafil. Arch Ophthalmol. 2009; 127(4):367-373.

42. Stockman A, Sharpe LT, Tufail A, Kell PD, Ripamonti C, Jeffery G. The effect of sildenafil citrate (Viagra) on visual sensitivity. $J$ Vis. 2007;7(8):4.

43. Dündar SO, Topalo Gcaron Lu A, Dündar M, Koçak I. Effects of sildenafil on blue-on-yellow and white-on-white Humphrey perimetry in 3 months regular use. Eye (Lond). 2006;20(7):810-813.

44. Dündar SO, Dayanir Y, Topaloğlu A, Dündar M, Koçak I. Effect of sildenafil on ocular hemodynamics in 3 months regular use. Int J Impot Res. 2006;18(3):282-286.

45. Donahue SP, Taylor RJ. Pupil-sparing third nerve palsy associated with sildenafil citrate (Viagra). Am J Ophthalmol. 1998;126(3):476-477.

46. Kehat R, Bonsall DJ, North R, Connors B. Ocular findings of oral sildenafil use in term and near-term neonates. J AAPOS. 2010;14(2):159-162.

47. Wirostko BM, Tressler C, Hwang LJ, Burgess G, Laties AM. Ocular safety of sildenafil citrate when administered chronically for pulmonary arterial hypertension: results from phase III, randomised, double masked, placebo controlled trial and open label extension. BMJ. 2012;344:e554. 


\section{Publish your work in this journal}

Drug Design, Development and Therapy is an international, peerreviewed open-access journal that spans the spectrum of drug design and development through to clinical applications. Clinical outcomes, patient safety, and programs for the development and effective, safe, and sustained use of medicines are the features of the journal, which has also been accepted for indexing on PubMed Central. The manuscript management system is completely online and includes a very quick and fair peer-review system, which is all easy to use. Visit http://www.dovepress.com/testimonials.php to read real quotes from published authors.

Submit your manuscript here: http://www.dovepress.com/drug-design-development-and-therapy-journal 